\title{
Studies on a Galactan from Norwegian Spruce Compression Wood (Picea abies Karst.)
}

\author{
HANS O. BOUVENG and HANS MEIER
}

Träkemiska avdelningen, Svenska Träforskningsintitutet, Stockholm, Sweden

\begin{abstract}
A galactan, containing about $13 \%$ uronic acid residues, was isolated from Norwegian spruce compression wood. Partial hydrolysis gave D-galactose and a number of neutral oligosaccharides, which were shown by paper chromatography and paper electrophoresis to belong to the same homologous series. The first member of this series was crystalline and identified as 4-O- $\beta$-D-galactopyranosyl-D-galactose. The neutral part of the polysaccharide must therefore be composed essentially of linear chains of $1: 4-\beta$-linked D-galactose residues.
\end{abstract}

t has been known for some time that compression wood on hydrolysis
yields a much higher proportion of galactose than normal wood 1 . In the
present investigation a polysaccharide containing galactose residues was
isolated from compression wood from Norwegian spruce (Picea abies Karst.)
and characterised. Acetone-extracted, milled compression wood, on extract-
ion with hot water, yielded only a small fraction (A). However, a large amount
of polysaccharide was isolated from the solution obtained on delignification
of the wood meal with chlorite. This fraction (B) contained about half the
galactose residues in the wood. Further extraction of the holocellulose succes-
sively with hot water, $14 \%$ potassium hydroxide and $24 \%$ potassium
hydroxide containing $3 \%$ boric acid ${ }^{2}$ yielded fractions C, D and E, respectiv-
ely. The results of these extractions are summarised in Table 1 .
Fractions B and C were subfractionated by precipitation with barium
hydroxide 3 , yielding precipitates B I and C I, and soluble fractions B II and
C II. From analysis of hydrolysates of these fractions (Table 1) it was evident
that B I was a fairly pure galactan containing $12.9 \%$ uronic acids and con-
taminated with small amounts of glucomannan. This fraction, representing
about $44 \%$ of the galactose residues originally present in the wood, was used
for the present investigation.
Arabogalactans have been isolated from several coniferous woods, includ-
ing spruce wood 4 , and the possibility was considered that the present galactan
might be derived from an arabogalactan, from which arabinose residues had
been hydrolysed during delignification. It was found, however, that a larch Acta Chem. Scand. 13 (1959) No. 9 
Table 1. Carbohydrate analyses of polysaccharide fractions from spruce compression wood.

\begin{tabular}{|c|c|c|c|c|c|c|}
\hline & $\begin{array}{l}\text { Yield } \\
\mathrm{g}\end{array}$ & $\begin{array}{c}\text { Galactose } \\
\%\end{array}$ & $\begin{array}{c}\text { Glucose } \\
\%\end{array}$ & $\underset{\%}{\text { Mannose }}$ & $\begin{array}{c}\text { Arabinose } \\
\%\end{array}$ & $\begin{array}{c}\text { Xylose } \\
\%\end{array}$ \\
\hline $\begin{array}{l}\text { Spruce compression wood, extrac- } \\
\text { ted with acetone (Klason lignin: } \\
38.8 \% \text { ) } \\
\text { A: } \mathrm{H}_{2} \mathrm{O} \text {-extract } \\
\text { B: Polysaccharides from the } \\
\text { delignification solution } \\
\text { B I: } \mathrm{Ba}(\mathrm{OH})_{2} \text { precipitate } \\
\text { B II: Centrifugate } \\
\text { Holocellulose (Klason lignin: } \\
\text { l.1 \%) } \\
\text { C: Polysaccharides from the } \mathrm{H}_{2} \mathrm{O} \\
\text { extract of the holocellulose } \\
\text { C I: Ba }(\mathrm{OH})_{2} \text { precipitate } \\
\text { C II: centrifugate } \\
\text { D: Polysaccharides from the } 14 \% \\
\text { KOH extract } \\
\text { E: Polysaccharides from the } 24 \% \\
\text { KOH }+3 \% \mathrm{H}_{3} \mathrm{BO}_{3} \text { extract } \\
\text { E I: Ba(OH) precipitate } \\
\text { Residue }\end{array}$ & $\begin{array}{r}21.4 \\
5.5 \\
208.0\end{array}$ & $\begin{array}{l}97.3 \\
72.1\end{array}$ & $\begin{array}{r}55.6 \\
4.5 \\
\\
\text { trace } \\
2.2 \\
\\
65.8\end{array}$ & $\begin{array}{l}11.5 \\
16.1\end{array}$ & $\begin{array}{r} \\
\text { trace } \\
\mathbf{3 . 7}\end{array}$ & $\begin{array}{r}10.7 \\
0.9 \\
\\
\text { trace } \\
20.1\end{array}$ \\
\hline
\end{tabular}

arabogalactan, after similar treatment, could be recovered unchanged. Furthermore the arabogalactans have highly branched structures, while the present polysaccharide gave a fairly strong film, characteristic for a polysaccharide with an essentially linear structure ${ }^{5 a}$. The infrared spectrum of the polysaccharide showed a strong band at $886 \mathrm{~cm}^{-1}$, indicating a $\beta$-pyranosidic structure ${ }^{6}$.

Hydrolysis gave D-galactose and a number of acidic components, four of which were isolated in a fairly pure state by chromatography on thick filter paper. One of these acids was very probably galacturonic acid. A preliminary examination by paper chromatography and electrophoresis of hydrolysates of the other three acids indicated that in addition to galactose, one of them contained galacturonic acid and the other two glucuronic acid.

The possibility that part of the galacturonic acid originated from pectic acid was examined but attempted fractionation with cetyl-trimethylammonium hydroxide (CTA-OH), which is known to precipitate acidic polysacchari$\operatorname{des}^{7}$, was not successful. A spectrophotometric investigation of the polysaccharide revealed the presence of about $9 \%$ lignin; by treatment with chlorine and extraction with ethanolic ethanolamine this value was reduced to $1 \%$. The delignified material on electrophoresis on glass paper gave a very elongated spot with $M_{\mathrm{G}}$-value ranging from about 0.45 to 0.97 . This indicated that the sample was highly polymolecular but no distinct components could be detected. Even after delignification the sample could not be separated by fractionation with CTA-OH into a neutral galactan and a pectic acid. This corroborates the results of the hydrolyses mentioned above, that showed that at least part

Acta Chem. Scand. 13 (1959) No. 9 
of the uronic acid is bound to the galactan. Whether these residues are present on the galactan chains as single residues or as chains of pectic acid type, as was recently suggested by Aspinall et al. ${ }^{8}$ for a galactan and a pectic acid from sisal hemp, could not be decided.

Since a nitrate ester of the galactan (N $11.8 \%$ ) was only partly soluble in acetone or butyl acetate, the osmotic pressure was determined on the sodium salt of the unsubstituted galactan in $0.1 \mathrm{~N}$ sodium chloride solution. The value obtained, $\overline{\mathrm{DP}}_{\mathrm{n}} 52$, is however rather uncertain since the sample also contained lignin.

Partial hydrolysis of the galactan and removal of the acidic components left a number of neutral sugars, which were fractionated by carbon column chromatography. The first four components were completely separated but only a partial separation was obtained of four more components which followed

Table 2. $R_{F}$ (solvent b) and $M_{\mathrm{G}}$ (borate buffer, $\mathrm{pH} 10$ ) values of the neutral components.

\begin{tabular}{|c|l|l|l|}
\hline Fraction No. & Component & $R_{F}$ & $M_{\mathrm{G}}$ \\
\hline $34-64$ & galactose & 0.39 & 0.95 \\
$116-148$ & galactobiose & 0.27 & 0.48 \\
$180-202$ & galactotriose & 0.19 & 0.40 \\
$210-230$ & galactotetraose & 0.14 & 0.35 \\
$232-246$ & galactopentaose & 0.10 & 0.32 \\
$243-255$ & galactohexaose & 0.07 & 0.31 \\
$253-270$ & galactoheptaose & 0.05 & 0.30 \\
$262-281$ & galactooctaose & 0.04 & 0.28 \\
\hline
\end{tabular}

these. D-Galactose and a galactobiose were obtained crystalline. The galactobiose, $[\alpha]_{\mathrm{D}}^{25}+67^{\circ}$ showed the same paper chromatographic and electrophoretic data and the same $\mathrm{X}$-ray diffraction pattern as the 4-O- $\beta$-D-galactopyranosyl-D-galactose isolated from white birch ${ }^{9}$, a sample of which was obtained by courtesy of Dr. T. E. Timell. Further its melting point $210-212^{\circ}$ was undepressed on admixture with Timell's sample. The $R_{F}$ and $M_{\mathrm{G}}$ values of the sugars are given in Table 2. The $R_{\mathrm{M}}$-values, plotted against $\mathrm{n}$, give a straight line (Fig. 1), indicating that the sugars belong to a homologous series of the general formula $I$.

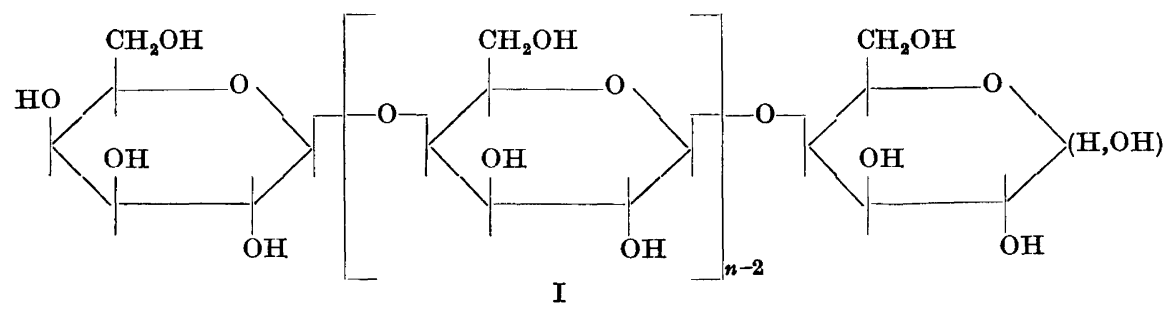

Acta Chem. Scand. 13 (1959) No. 9 
Fig. 1. Relation between $R_{\mathrm{M} \text {-values and }}$ chain length.

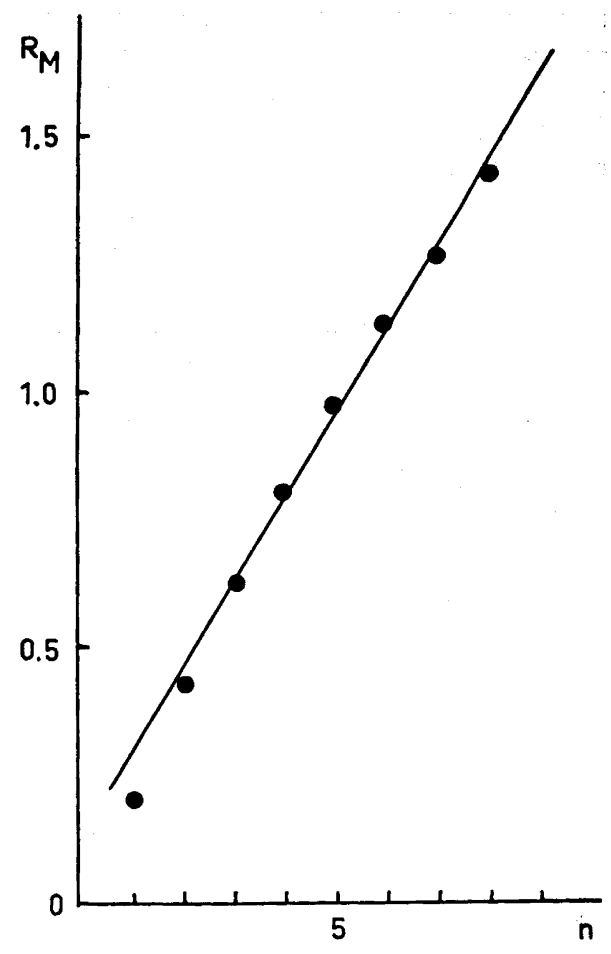

The electrophoretic data are also in agreement with this conclusion and each of the components on partial hydrolysis yielded all the lower oligosaccharides. Only traces of neutral oligosaccharides, other than those belonging to this series, were observed in the hydrolysate of the galactan, and the galactan must therefore be composed essentially of linear chains of $\beta$-1,4-linked $D$ galactose residues. Uronic acid residues are linked to some of these. The nature of these linkages and the question of whether some of the uronic acid residues are present in pectic acid chains must await further study.

The galactan from spruce compression wood is thus of similar type to that belonging to the pectic triad ${ }^{5 b}$. A similar galactan has recently been obtained by Andrews et al. ${ }^{10}$ from Strychnos nux vomica seeds and the isolation of 4- $\beta$-D-galactopyranosyl-D-galactose by Gillham and Timell ${ }^{11}$ from a hydrolysate of white birch $\alpha$-cellulose also indicates the presence of a polysaccharide of this type. The presence of pectic substances in the middle lamella of wood fibres has long been assumed, and it has recently been demonstrated ${ }^{12,13}$, that the middle lamella of unripe aspen fibres and of pine tracheids contain a high percentage of polymers, built up from galactose, arabinose and galacturonic acids, which are the constituent sugars of the pectic triad. Although a large part of the galactans from the compression wood was extracted during the delignification, a considerable part remained undissolved even after treat- 
ment with $14 \%$ potassium hydroxide. This does not necessarily imply that the wood contains galactans that are structurally very different. The same difference has also been observed in spruce glucomannans ${ }^{14}$, two extreme fractions of which showed some difference in DP but had eseentially the same chemical structure.

\section{EXPERIMENTAL}

Melting points are corrected. Optical rotations were determined in water: $c, 1.5$. The concentration of solutions was done under reduced pressure, at a bath temperature of about $40^{\circ}$.

Paper chromatograms were run on Whatman No. 1 and 3 MM papers, using the solvent systems $(v / v)$ :

a) Ethyl acetate-acetic acid-water, 3:1:3 (upper phase)

b) Ethyl acetate-pyridine-water, 2:1:2 (upper phase).

The method of Saeman et al. ${ }^{15}$ was used for quantitative determinations. Paper electrophoreses were run on Schleicher and Schüll glass fibre papers and on Whatman No. $3 \mathrm{MM}$ paper in $0.1 \mathrm{M}$ borate buffer of $\mathrm{pH} 10$ or $0.1 \mathrm{M}$ acetate buffer of $\mathrm{pH} 4$.

Isolation and fractionation of polysaccharides. Acetone-extracted wood meal (18-35 mesh) was extracted with hot water. Acidification and precipitation with ethanol, yielded fraction $\mathrm{A}$. The wood meal was then delignified by the chlorite method at $60^{\circ}$ and $\mathrm{pH}$ 4.7. The combined chlorite solutions were dialysed against running tap water for 11 days, acidified and precipitated with ethanol, yielding fraction B. The holocellulose was then extracted successively with hot water, $14 \%$ potassium hydroxide and $24 \%$ potassium hydroxide with $3 \%$ boric acid. The latter two extractions were made under nitrogen, and the polysaccharides extracted were recovered by precipitation with ethanol (fractions $\mathrm{C}, \mathrm{D}$ and $\mathrm{E}$ respectively).

Fractions $B$ and $C$ were dissolved in water and a saturated solution of barium hydroxide was added ${ }^{3}$. The material in the precipitates and in the supernatants was recovered, yielding fractions B I, C I and B II, C II respectively.

B I was delignified with chlorine and ethanolic ethanolamine, as described previously ${ }^{16}$. Treatment with cetyl-trimethylammonium hydroxide (CTA-OH) precipitated about 2/3 of the material. The precipitate and the material remaining in solution were isolated as described by Bouveng and Lindberg ${ }^{17}$. They had optical rotations of $+80^{\circ}$ and $+55^{\circ}$, resp., the first fraction having a considerably higher content of uronic acid residues. Attempted fractionation of undelignified material with CTA-OH failed.

B I was readily soluble in water, $[\alpha]_{D}^{28}+57^{\circ}$. It contained about $9 \%$ lignin ${ }^{16}$ and $12.9 \%$ of uronic acid residues ${ }^{18}$, calculated as galacturonic acid. The $\overline{\mathrm{DP}}_{\mathrm{n}}$ was determined osmometrically as already described for an araboglucuronoxylan ${ }^{18}$.

Hydrolysis of $B I$. A solution of B I $(3 \mathrm{~g})$ in $4 \%$ sulphuric acid $(800 \mathrm{ml})$ was kept at $120^{\circ}$ for $1 \mathrm{~h}$ and then neutralised with barium hydroxide. The neutral solution was passed successively through columns of Dowex $50(\mathrm{H}+)$ and Dowex 3 (free base) ion exchange resin. D-Galactose was recovered from the deionised solution. The acids were eluted from the anion exchange resin with $1 \mathrm{~N}$ ammonium hydroxide and the solution obtained was concentrated to a syrup. Electrophoresis and paper chromatography (solvent a) revealed the presence of galacturonic acid and of at least three acids with lower $R_{F}$ values. The latter were separated by chromatography on thick filter paper. A chromatographic and electrophoretic examination of these acids after hydrolysis with $6 \%$ sulphuric acid at $120^{\circ}$ for $6 \mathrm{~h}$ indicated that one of them contained galactose and galacturonic acid while the other two were composed of galactose and, probably, glucuronic acid.

Partial hydrolysis of BI. A sample of BI $(3 \mathrm{~g})$ was heated with $\mathrm{N}$ sulphuric acid $(200 \mathrm{ml})$ for $40 \mathrm{~min}$ on a steam bath, cooled and deionised. The solution was concentra. ted to $10 \mathrm{ml}$ and then adsorbed on a carbon-Celite column $(4 \times 45 \mathrm{~cm})$. Gradient elution with aqueous ethanol, $1-10 \%(41)$ followed by $10-35 \%(61)$ effected a separation of the components. The first four members, galactose to galactotetraose were completely separated. From the pentaose to the octaose they only partially separated, but relatively 
pure top fractions were obtained of all components. The $R_{F}$ - and $M_{\mathrm{G}}$-values of the components are given in Table 2.

D-Galactose $(346 \mathrm{mg}),[\alpha]_{\mathrm{D}}^{25}+82^{\circ}, \mathrm{m} . \mathrm{p} .164-167^{\circ}$, undepressed on admixture of an authentic sample.

Galactobiose $(278 \mathrm{mg}),[\alpha]_{25}^{\mathrm{D}}+67^{\circ}$, m. p. 210-212 $2^{\circ}$, alone or mixed with $\beta$-1,4-galactobiose, kindly supplied by Dr. T. E. Timell, Montreal. The X-ray diffraction pattern was identical with that reported by Gillham et al. $0^{\circ}$ The $M_{\mathrm{G}}$-value in borate buffer, 0.48 , was, as expected, lower than the values reported for the corresponding $\beta$-1,3- and $\beta$-1,6-linked disaccharides ${ }^{19}(0.69$ and 0.84$)$.

Galactotriose $(213 \mathrm{mg}),[a]_{\mathrm{D}}^{25}+58^{\circ}$. Amorphous.

Galactotetraose $(151 \mathrm{mg}),[\alpha]_{\mathrm{D}}^{25}+53^{\circ}$. Amorphous.

Acknowledgment. The authors thank Docent B. Lindberg for his keen interest in this work.

\section{REFERENCES}

1. Stockman, L. and Hägglund, E. Svensk Papperstidn. 51 (1948) 269.

2. Jones, J. K. N., Wise, L. E. and Jappe, J. P. Tappi 39 (1956) 139.

3. Meier, H. Acta Chem. Scand. 12 (1958) 144.

4. Adams, G. A. Can. J. Chem. 36 (1958) 755.

5. a. Whistler, R. L. and Smart, C. L. Polysaccharide Chemistry, New York 1953, p. 32.

5. b. Ibid. p. $16 \mathrm{I} \mathrm{ff}$.

6. Barker, S. A., Bourne, E. J., Stephens, R. and Whiffen, D. H. J. Chem. Soc. 1954 3468.

7. Scott, J. E. Chem. \& Ind. London 1955168.

8. Aspinall, G. O. and Cañas-Rodriguez, A. J. Chem. Soc. 19584020.

9. Gillham, J. K., Perlin, A. S. and Timell, T. E. Can. J. Chem. 36 (1958) 1741.

10. Andrews, P., Hough, L. and Jones, J. K. N. J. Chem. Soc. 1954806.

11. Gillham, J. K. and Timell, T. E. Svensk Papperstidn. 61 (1958) 540.

12. Sultze, R. F. Tappi 40 (1957) 985.

13. Meier, H. Svensk Papperstidn. 62 (1959) 687.

14. Croon, I. and Lindberg, B. Acta Chem. Scand. 12 (1958) 453.

15. Saeman, J. F., Moore, W. E., Mitchell, R. L. and Millet, M. A. Tappi 38 (1954) 336.

16. Meier, H. Acta Chem. Scand. 12 (1958) 1911.

17. Bouveng, H. O. and Lindberg, B. Acta Chem. Scand. 12 (1958) 1977.

18. Johansson, A., Lindberg, B. and Theander, O. Svensk Papperstidn. 57 (1954) 41.

19. Bouveng, H. O. and Lindberg, B. Acta Chem. Scand. 10 (1956) 1283.

Received June 3, 1959.

Acta Chem. Scand. 13 (1959) No. 9 